\title{
KRISIS DOKLAM DAN KEPENTINGAN NASIONAL INDIA
}

\author{
Vida Mardiana \\ UIN Syarif Hidayatullah Jakarta \\ Email : Vida.mardian@gmail.com
}

\begin{abstract}
ABSTRAK
Krisis Doklam yang terjadi di tahun 2017 meningkatkan tensi pada hubungan Tiongkok dan India. Hal ini bermula pada saat Tiongkok membangun infrastruktur berupa jalan raya di wilayah perbatasannya dengan Bhutan dihadang oleh tentara India yang datang atas nama Bhutan dan memaksa Tiongkok untuk menghentikan aktifitasnya. Ketegangan yang terjadi selama 73 hari antara India dan Tiongkok ini menarik untuk dikaji. India yang sebenarnya tidak berbatasan langsung dengan Tiongkok di wilayah Doklam bersedia untuk menurunkan tentaranya pada konflik antara Tiongkok dan Bhutan ini. Tujuan tulisan ini selain untuk menjelaskan krisis yang terjadi, juga untuk mengetahui alasan India ikut terlibat langsung dalam konflik ini. Dengan menggunakan metode kualitatif deskriptif, tulisan ini akan menganalisis sumber sekunder yang berasal dari buku, artikel jurnal, atau literature lainnya di media masa. Konsep yang digunakan adalah konsep national interest. Dari tulisan ini, diketahui bahwa alasan dibalik tindakan India terlibat secara langsung dalam konflik di Doklam bahkan hingga menurunkan militernya adalah karena adanya kepentingan pertahanan dan keamanan dan kepentingan ekonomi India yang harus dilindungi.
\end{abstract}

Kata Kunci: Krisis Doklam, kepentingan nasional, pertahanan dan keamnan, ekonomi, India

\begin{abstract}
The Doklam crisis that occurred in 2017 increased the tension in the relationship between China and India. This started when China built infrastructure in the form of a highway on its border with Bhutan which was blocked by Indian soldiers who came on behalf of Bhutan and forced China to stop its activities. The tensions that lasted for 73 days between India and China are interesting to study. India, which is actually not directly adjacent to China in the Doklam region, is willing to deploy its troops in this conflict between China and Bhutan. The purpose of this paper is not only to explain the crisis that occurred, but also to find out why India was directly involved in this conflict. By using a descriptive qualitative method, this paper will analyze secondary sources from books, journal articles, or other literature in the mass media. The concept used in this paper is the concept of national interest. From this paper, it is known that the reason behind India's actions to be directly involved in the conflict in Doklam and even to deploy its troops was because of India's defense and security interests and economic interests that must be protected.
\end{abstract}

Keywords: Doklam crisis, national interest, defence and security interests, economic interests, India

\section{PENDAHULUAN}

Sengketa wilayah menjadi permasalahan antar negara yang sangat sulit diselesaikan. Menjaga kedaulatan wilayah negara bukan hanya masalah mempertahankan harga diri pertahanan dan keamanan sebuah negara, tetapi juga memperebutkan apa yang dapat menguntungkan negara tersebut. Karena wilayah yang luas tentu saja juga diiringi dengan sumber daya alam yang dapat diolah. Tumpang tindihnya klaim atas suatu wilayah yang berada di perbatasan negara-negara seringkali memanaskan tensi hingga memercikkan api konflik antara negara yang sama-sama mengklaim. 
Tiongkok adalah negara yang memiliki banyak sengketa perbatasan wilayah dengan negara berbeda. Salah satunya yaitu sengketa perbatasan dengan Bhutan dan India di Doklam yang memanas pada Juni 2017 lalu. Doklam adalah sebuah wilayah dataran tinggi yang berada di kawasan Himalaya yang membatasi secara langsung Tiongkok dengan Bhutan.

Sengketa ini bermula karena pembangunan jalan yang dilakukan oleh People's Liberations Army (PLA) pada 16 Juni 2017 di Dataran Tinggi Doklam. Pembangunan jalan raya oleh Tiongkok yang dilakukan di Doklam menuju kamp Tentara Bhutan di Zompelri (Ministry of Foreign Affairs of Bhutan, 2017) tentu saja membawa kekhawatiran bagi Bhutan. Bhutan dan India menganggap aktifitas Tiongkok yang semakin dekat dengan wilayah territorial Bhutan tersebut adalah sebuah ancaman bagi stabilitas keamanan wilayahnya.

Setelah mendengar Tiongkok melakukan pembangunan jalan raya di daerah tersebut, India "atas nama Bhutan" langsung menempatkan militernya untuk mengawasi Tiongkok agar tidak melewati batas territorial wilayah Bhutan. Tindakan India ini dilakukan dengan alasan Bhutan merupakan sekutunya berdasarkan Indian-Bhutan Friendship Treaty 2007. Ikatan kerjasama ekonomi dan militer ini menyatakan bahwa India berhak memberi jaminan keamanan untuk Bhutan apabila mendapat ancaman eksternal dari negara lain. (IndianBhutan Friendship Treaty, 2007). Bhutan juga sejak kemerdekaanya sangat bergantung terkait masalah keamanan teritorial, politik luar negeri, hingga perekonomian terhadap India. Tetapi menurut Tiongkok, keberadaan India di perbatasan Bhutan merupakan suatu wujud dari intervensi militer dan mengganggu kedaulatan Bhutan. Kehadiran Tentara India di wilayah perbatasan justru memicu terjadinya konflik dengan PLA. (Chang, 2017). Ketegangan antara India-Tiongkok itu akhirnya berakhir setelah terjadi selama 73 hari, yaitu sejak 16 Juni hingga 28 Agustus 2017. Hal ini ditandai dengan terjadinya peristiwa Doklam Standoff, yaitu mundurnya tentara Tiongkok dan India dari wilayah tersebut.

Hubungan diplomatik antara India dan Tiongkok yang sudah terbangun sejak tahun 1949 diwarnai dengan kerja sama dan tensi. Tahun 1959 menjadi fase buruk bagi kedua negara khususnya mengenai isu perbatasan. (Kumar, 1963). Kawasan perbatasan dengan India menjadi salah satu sengketa perbatasan yang belum diselesaikan oleh Tiongkok hingga saat ini. Isu Doklam sebenarnya hanyalah salah satu dari sejumlah panggung geopolitik antara India dan Tiongkok, walau mungkin krisis ini tidak akan bertransformasi menjadi perang yang lebih besar. 
Konflik yang terjadi di Doklam ini menjadi lebih menarik lagi karena kehadiran India yang bahkan tidak berbatasan langsung dengan Tiongkok tetapi dengan sesegera mungkin mengerahkan tentaranya di wilayah tersebut untuk melakukan pemblokiran. Keterlibatan India militer India di lapangan membuat konflik ini tidak terlihat seperti konflik antara Tiongkok dengan Bhutan, melainkan Tiongkok dengan India. Fenomena keterlibatan militer India yang segera siaga setelah mendengar pembangunan jalan raya yang dilakukan Tiongkok ini menimbulkan pertanyaan yang menarik untuk dikaji lebih lanjut. Sehingga tulisan ini akan berusaha menjawab terkait apa sebenarnya yang menjadi alasan keterlibatan India atau kepentingan apa yang sedang India coba lindungi di konflik ini. Tujuan penelitian ini adalah untuk mengetahui kepentingan yang sedang India pertahankan sehingga rela menurunkan tentaranya untuk menghadang perbatasan yang bahkan tidak menyentuh wilayah teritorialnya.

\section{KERANGKA ANALISIS}

Konsep national interest atau kepentingan nasional merupakan konsep paling umum dalam membahas hubungan luar negeri antar Negara. Konsep ini juga merupakan alat untuk menjelaskan prilaku sebuah Negara dalam interaksinya di dunia internasional. Sulit ditemukan analisis hubungan internasional yang tidak menyinggung tentang kepentingan nasional.

Menurut Scott Burchill, kepentingan nasional adalah motivasi suatu Negara dalam menjalankan kebijakan politik luar negerinya. Dan menurut Charles Bread, kepentingan nasional adalah alasan Negara dibelakang tujuan-tujuan dan ambisinya dalam menjalankan hubungan internasional. Intinya, para penstudi menggunakan konsep kepentingan nasional ini untuk menggambarkan dan menganalisis alasan, motivasi, atau justifikasi utama yang menjadi dasar suatu Negara berperilaku atau bertindak dalam interaksinya dengan Negara lain. (Bakry, 2017).

Menurut Hans. J Morgenthau, kepentingan nasional setiap negara adalah mengejar power yaitu apa saja yang bisa membentuk dan mempertahankan pengendalian suatu Negara atas Negara lain. (Mas'oed, 1990). Morgenthau juga membagi kepentingan nasional ke dalam dua tingkat, yaitu kepentingan nasional primer (vital) dan kepentingan nasional sekunder. Kepentingan nasional primer ini terkait dengan perlindungan terhadap identitas fisik, politik, dan budaya serta keamanan dan keberlangsungan hidup suatu negara. Dalam mencapai kepentingan vital ini bahkan sebuah negara tidak segan untuk berperang. 
Sedangkan kepentingan sekunder adalah kepentingan yang masih dapat dinegosiasikan dengan Negara lain. (Bakry, 2017).

Donald E. Nuechterlein, mengklasifikasikan kepentingan nasional ke dalam empat kepentingan dasar Negara (basic interest) yang memotivasi suatu negara untuk menjalankan hubungan luar negerinya. Pertama adalah kepentingan pertahanan dan keamanan (defence interest). Kepentingan ini menyangkut perlindungan terhadap wilayah dan warga suatu negara bangsa dari ancaman oleh negara lain. Kedua yaitu kepentingan ekonomi (economic interest). Kepentingan ini untuk meningkatkan ekonomi negara dengan cara menumbuhkan relasi atau kerjasama dengan negara lain. Ketiga adalah kepentingan tatanan internasional (world order interest). Kepentingan tata dunia yaitu adanya jaminan pemeliharaan terhadap sistem politik dan ekonomi internasional dimana suatu negara dapat merasakan suatu keamanan sehingga rakyat dan badan usaha dapat beroperasi di luar batas negara dengan aman. Dan yang keempat adalah kepentingan ideologi (ideologic interest). Kepentingan ini merupakan kepentingan negara untuk melindungi dan mempertahankan nilai-nilai ideologi negaranya dari ancaman ideologi negara lain. (Nuechterlein, 1979).

Pertahanan dan keamanan berperan sangat penting dalam menjaga kepentingan dasar negara yang telah diklasifikasikan Nuechterlein. Strategi pertahanan dan keamanan yang bagus dapat mendukung kebijakan ekonomi dan kebijakan luar negeri lainnya dalam dunia internasional. Negara yang memiliki pertahanan dan keamanan yang kuat akan mampu mengawal ketiga kepentingan dasar lainnya, yakni kepentingan ekonomi, kepentingan sistem tata internasional dan kepentingan ideologi. Karena pertahanan dan kemanan yang kuat membawa rasa percaya diri yang besar bagi Negara untuk berinteraksi dengan Negara lain.

Nuechterlein selanjutnya menganggap bahwa kepentingan ekonomi merupakan kepentingan yang krusial selain kepentingan pertahanan. Di samping itu juga dewasa ini ekonomi merupakan sumber kekuatan baru yang membuat sebuah Negara disegani di mata dunia. Kepentingan ekonomi yang didefinisikan Nuechterlein adalah kepentingan yang dilaksanakan pemerintah untuk meningkatkan perekonomian negara melalui kerja sama ekonomi dengan negara lain sehingga terjalin hubungan dagang yang menghasilkan keuntungan. Hal ini menunjukan bahwa kepentingan ekonomi berperan penting dalam meningkatkan kesejahteraan hidup masyarakat dalam suatu negara. 
Tulisan ini akan menganalisis kepentingan keterlibatan India dalam sengketa perbatasan di Doklam dengan dua dari empat kepentingan dasar yang disebutkan Nuechterlein, yaitu kepentingan pertahanan dan kemanan, dan kepentingan ekonomi.

\section{METODE PENELITIAN}

Metode penelitian yang digunakan dalam rangka mencoba menjawab pertanyaan penelitian dalam tulisan ini adalah metode penelitian kualitatif deskrptif. Jenis data yang diperoleh dan digunakan untuk penelitian ini adalah jenis data primer dan sekunder. Data primer diambil dari dokumen resmi pemerintah seperti dokumen perjanjian yang tersedia di laman resmi institusi, seperti situs resmi pemerintahan India ataupun yang terkait dengan penelitian ini. Sementara data sekunder berasal dari tulisan akademik berupa buku cetak, e-book, jurnal ataupun sumber yang berasal dari situs media nasional maupun internasional khususnya media daring yang sekiranya diperlukan untuk menjawab pertanyaan penelitian. Sehingga diharapkan tulisan ini menjadi kaya perspektif tetapi tidak keluar dari tujuan utama tulisan.

\section{PEMBAHASAN}

\section{Konflik Perbatasan Tiongkok-Bhutan di Doklam dan Keterlibatan India}

Konflik perbatasan Tiongkok dengan Bhutan di dataran tinggi Doklam sebenarnya bukan hal baru. Bahkan Doklam bukan satu-satunya wilayah yang diperebutkan oleh kedua Negara tersebut. Konflik yang sudah bermula dari lama ini sayangnya tidak juga menemukan ujung jalan. Akhirnya hingga kini Doklam merupakan wilayah status quo. Hubungan antara Tiongkok dan Bhutan juga tidak bisa dikatakan harmonis jika melihat sejarah mereka mengenai perbatasan wilayah mereka.

Dataran tinggi Doklam terletak di pertigaam (tri-junction) India, Cina dan Bhutan di daerah strategis Lembah Chumbi yang mengarah ke jalur Doka La yang menghubungkan Tibet dengan Sikkim, daerah Doklam atau masyarakat Tiongkok biasa menyebutnya Donglang, telah menjadi sengketa teritorial antara Tiongkok dan Bhutan dan kedua negara telah sepakat pada tahun 1998 untuk tidak mengubah status quo di wilayah tersebut sampai tercapainya penyelesaian yang dapat diterima keduanya. Sejak 1984, kedua negara telah mengadakan sekitar 24 kali pembicaraan untuk penyelesaian perbatasan mereka yang di dalamnya juga termasuk untuk sengketa Doklam, tetapi sejauh ini belum ada kesepakatan akhir yang ditandatangani. (Bala, 2017)

Sengketa perbatasan wilayah ini kembali memanas berawal karena pada tanggal 16 Juni 2017 People's Liberations Army (PLA) membangun jalan raya yang dapat dilalui 
kendaran bermotor dari Doka La di daerah Doklam menuju kamp Tentara Bhutan di daerah Zompelri. Kemudian pada tanggal 18 Juni 2017, India menurunkan tentaranya untuk menghadang pembangunan infrastruktur tersebut. Tiongkok yang merasa geram langsung membawa masalah ini ke publik dan melakukan konferensi pers pada 28 Juni 2017. Juru bicara kementrian Luar Negeri Tiongkok pada saat itu, Lu Kang, menegaskan bahwa Doklam telah menjadi bagian dari Tiongkok sejak zaman kuno. Doklam bukan milik Bhutan, terlebih India. Itu adalah fakta yang tak terbantahkan yang didukung oleh bukti sejarah dan yurisprudensial, dan situasi lapangan. Sangat tidak bisa dibenarkan jika pihak India ingin mempermasalahkannya. Pembangunan jalan raya Tiongkok di Doklam merupakan tindakan kedaulatan di wilayahnya sendiri. Itu sepenuhnya dibenarkan dan sah, dan pihak lain tidak memiliki hak untuk ikut campur. (Menon \& Kanisetti, 2020).

Keesokan harinya, pada tanggal 29 Juni 2017, Kementrian Luar Negeri Bhutan mengeluarkan Press Release yang menegaskan sikapnya terhadap Tiongkok. Bhutan mengatakan bahwa pihaknya dan Tiongkok telah menyepakati perjanjian tahun 1998 untuk menjaga perdamaian dan ketenangan di daerah perbatasan mereka sambil menunggu penyelesaian akhir sengketa, juga untuk tetap mempertahankan status quo di perbatasan seperti sebelum Maret 1959. Dalam perjanjian itu juga dikatakan bahwa kedua pihak telah setuju untuk menahan diri dari menagambil tindakan sepihak atau menggunakan kekuatan untuk mengubah status quo wilayah perbatasan tersebut. Bhutan juga telah menyampaikan kepada pihak Tiongkok, bahwa pembangunan jalan di dalam wilayah Bhutan merupakan pelanggaran langsung terhadap perjanjian dan mempengaruhi proses penetapan batas antara kedua negara kita. Bhutan berharap status quo di kawasan Doklam dapat terus bertahan seperti sebelum 16 Juni 2017. (Ministry of Foreign Affairs of Bhutan, 2017)

Klaim Tiongkok atas wilayah dataran tinggi Doklam adalah berdasarkan pada Convention between Great Britain and China relating to Sikkim and Tibet 1890. Pasal 1 konvensi tersebut berbunyi:

"The boundary of the Sikkim and Tibet shall be the crest of the mountain range separating the waters flowing into the Sikkim Teesta and its affluent from the waters flowing into the Tibetan Mochu and northwards into other rivers of Tibet. The line commences at Mount Gipmochi and follows the above mentioned water parting to the point where it meets Nipal territory."

Tiongkok telah menggunakan konvensi ini untuk mengklaim pertigaan IndiaTiongkok-Bhutan di Gipmochi atau Gymochen yang dalam bahasa China disebut Jimu Mazhen. Namun, menurut fitur geografis, 'daerah aliran sungai' dan 'the crest of the mountain' atau 'puncak gunung' tidak terbentang melebihi Batang La, yaitu enam kilometer 
sebelah utara Doka La. Interpretasi inilah yang dipegang oleh Bhutan dan India dan telah membuat marah Tiongkok. Tiongkok sebenarnya sejak awal 2000-an telah membangun jalan yang dapat dilalui kendaraan bermotor ke Shinche La atau dalam bahasa China disebut Shenjiula. Namun, saat ini China ingin memperluasnya ke Punggung Bukit Jampheri atau masyarakat Bhutan menyebutnya Zompelri, di dekat Doka La, kira-kira lebih dari 2 kilometer sebelah utara Gipmochi. (Deepak, 2017).

Dibiarkan sendiri, bangsa Bhutan, dengan kurang dari satu juta penduduk itu tentu akan kewalahan dalam mempertahankan masalah teritorial apa pun yang dibuat oleh Tiongkok, negara dengan penduduk sekitar 1,3 miliar jiwa dan memiliki ekonomi terkuat kedua di dunia. Bhutan yang telah mengizinkan India secara de jure menangani masalah keamanan dan kebijakan luar negerinya selama beberapa dekade, tidak memiliki hubungan diplomatik dengan Tiongkok. Kemudian, di bawah perjanjian persahabatan tahun 1949 antara Bhutan dan India, New Delhi bertanggung jawab atas pertahanan dan kebijakan luar negeri Bhutan. Pada tahun 2007, perjanjian itu direvisi, dengan Bhutan memperoleh otonomi yang lebih besar. Namun demikian, India mempertahankan komitmennya pada kerajaan tersebut. Perjanjian 2007 itu mencatat bahwa 'tidak ada Pemerintah yang mengizinkan penggunaan wilayahnya untuk kegiatan yang membahayakan keamanan nasional dan kepentingan pihak lain.' Bahkan jika Bhutan bersedia membiarkan Tiongkok menguasai Doklam, India kemungkinan besar tidak akan bersedia untuk minggir, apalagi dengan adanya perjanjian tersebut yang tidak mengharuskan India untuk menyingkir. (Maitra, 2018).

India dan Tingkok kemudian menyepakati untuk menerapkan kebijakan "expeditious disengagement", yaitu menarik mundur pasukan di daerah perbatasan yang disengketakan setelah diplomasi yang matang. Mereka tentu tidak mendapat keuntungan jika ketegangan terus berlanjut. Setiap eskalasi lebih lanjut dapat menimbulkan biaya yang sangat besar dalam hal keterlibatan ekonomi, biaya politik dan diplomatik, dan korban jiwa. (Ratha, 2020). Di sisi lain, India sangat membutuhkan pasar Tiongkok untuk pertumbuhannya di masa depan. India dan Tiongkok telah membuat perjanjian di bidang perekonomian berupa perjanjian perdagangan. Tiongkok dan India telah melakukan perdagangan bebas, dan memiliki kerja sama di bidang perekonomian. Salah satu sebab mengapa krisis doklam diakhiri dengan kebijakan expeditious disengagement juga karena adanya pertemuan BRICS, di mana kerja sama multilateral ini mempertemukan India dan Tiongkok sehingga 
dapat menjembatani keduanya untuk bernegosiasi ketika ketegangan berlangsung. (Rejeki \& Utomo, 2019). Setelah ketegangan militer yang terjadi di dataran tinggi Doklam selama 73 hari dari pertengahan bulan Juni hingga akhir bulan Agustus 2017, India dan Tiongkok akhirnya mengalami kebuntuan militer dan menarik mundur pasukannya dari Doklam. Peristiwa ini lah yang disebut Doklam Standoff.

\section{Analisis Ancaman dan Kepentingan Nasional India}

Fenomena turun tangannya India langsung dalam sengketa perbatasan wilayah di Doklam ini tentu saja mengundang minat para pengkaji. Sengketa batas territorial antara Tiongkok dan Bhutan yang sama sekali tidak menyentuh territorial wilayah India, ampuh mengusik India hingga mengerahkan pasukan militernya langsung ke lapangan. Kenyataan ini tentu memiliki latar belakang kepentingan India terhadap krisis tersebut.

Terlepas dari perjanjian persahabatan antara India dan Bhutan pada tahun 2017 yang memberi hak pada India untuk memberi jaminan keamanan terhadap Bhutan, faktanya, pembangunan jalan raya yang dilakukan PLA Tiongkok di Doka La daerah Doklam ini memungkinkan terbukanya akses yang lebih mudah bagi masyarakat atau militer Tiongkok untuk mendatangkan mobilitas dengan waktu tempuh kurang dari 24 jam dari Yadong ke Doka La. Hal ini tentu menjadi ancaman serius, bukan hanya bagi Bhutan yang berbatasan langsung dengan Tiongkok, tetapi juga bagi pertahanan dan keamanan India karena Doka La merupakan daerah titik temu perbatasan India, Tiongkok, dan Bhutan yang sangat dekat dengan 'chicken's neck' India.

Daerah Silliguri corridor yang juga disebut Chicken's neck ini merupakan wilayah yang penting bagi India. Daerah ini sangat sensitif karena menghubungkan daratan India dengan tujuh negara bagian timur lautnya. India memandang aktivitas Tiongkok untuk membangun jalan di wilayah tersebut lebih sebagai tantangan keamanan yang dapat mengancam keselamatan rakyatnya dan kendali atas kedaulatan teritorialnya sendiri, dari pada sebagai sengketa perbatasan belaka. (Raju, 2020).

Selain dianggap mengancam kedaulatan wilayahnya, pembangunan jalan raya yang dilakukan oleh Tiongkok untuk menhubungkan daerah Yadong dengan Doka La juga dianggap sebagai ancaman serius untuk perekonomian India. Pasalnya, akses yang mudah adalah poin penting dalam sektor perekonomian. Daerah yang memiliki infrastruktur yang baik dan dapat dengan mudah mengakses layanan publik tentu perekonomiannya juga akan 
lebih baik. Apalagi jika daerah tersebut dapat mengakses dengan mudah wilayah ibu kota yang.

Mengingat infrastruktur yang baik salah satu tujuannya adalah untuk kemajuan ekonomi, tentu India geram dan menganggap bahwa pembangunan jalan raya oleh Tiongkok di wilayah tersebut adalah sebuah serangan bagi India. Thimpu yang merupakan ibu kota dari Bhutan secara geografis letaknya justru lebih dekat dengan Yadong yang merupakan wilayah di mana aktivitas pembangunan jalan raya tersebut berlangsung. Melihat itu, kemungkinan Yadong akan menjadi daerah yang menjadi persinggahan pasokan dari wilayah Chengdu, Tiongkok dan memungkinkan untuk Bhutan serta wilayah Assam, India untuk melakukan aktivitas ekonomi dengan mudah di sana. Hal itu tentu karena kemudahan aksesibilitas yang pada akhirnya dapat mengefisiensi waktu maupun biaya pada proses produksi.

Di samping itu, Bhutan merupakan pasar yang sangat potensial bagi India. Beberapa barang yang diimpor Bhutan dari India, di antaranya mineral, minyak, besi dan baja. Di samping itu, Bhutan juga mengekspor barang-barang yang penting untuk India, di antaranya sulfur, batu, plaster, dan semen. India merupakan partner dagang terbesar bagi Bhutan. Salah satu kerja sama bidang ekonomi yang menguntungkan untuk keduanya adalah kerja sama hydropower.

Bhutan merupakan negara yang berlimpah air. Hal ini menjadikan sektor tenaga air sebagai penyumbang penting bagi perekonomiannya. Bhutan memiliki kapasitas untuk menghasilkan sekitar 30.000 megawatt pembangkit listrik tenaga air setiap tahun. Dari jumlah tersebut, saat ini hanya sekitar 1.616 megawatt yang dihasilkan. Bahkan pada tingkat ini, ekspor energi tenaga air menghasilkan sekitar 40 persen dari pendapatan Bhutan. Kontribusi sektor ini terhadap produk domestik bruto (PDB) negara sekitar 25 persen. Namun, Bhutan tidak dapat memanfaatkan energi tenaga air karena kurangnya dana dan teknologi. Untuk itu Bhutan bergantung pada India. Akibatnya, sejumlah perusahaan pembangkit listrik tenaga air India beroperasi di Bhutan. (Ranjan, 2018).

Sayangnya, kerja sama hydropower antara Bhutan dan India ini hanya meperkuat perekonomian Bhutan saja. Pembangkit listrik tenaga air ini tidak mampu menekan angka pengangguran Bhutan. Namun, Tiongkok, saingan geopolitik India, sangat ingin meredakan kekhawatiran tersebut, meskipun dengan motif tersembunyi. Jika hubungan ekonomi IndiaBhutan berpusat pada tenaga air, Bhutan dapat menyambut baik tawaran pembangunan 
ekonomi Tiongkok dan mungkin saja tuntutan teritorial strategis berikutnya. Kemudian, Bhutan, satu-satunya tetangga setia India, menjadi target Tiongkok. Meskipun Bhutan tetap khawatir akan mengecewakan India, tetapi para pemimpin Bhutan telah menyuarakan ketertarikan mereka untuk meningkatkan kerja sama ekonomi dengan Tiongkok. Ketertarikan Bhutan terhadap program pendanaan Tiongkok Belt and Road Initiative (BRI) disuarakan oleh Perdana Menteri Bhutan, Tshering Togbay dalam pidato parlemennya pada bulan Juni 2018. (Wischer, 2019). Bhutan berharap kerja sama ekonomi dengan Tiongkok ini dapat membantunya mengatasi masalah angka pengangguran yang tinggi. Niat Bhutan untuk mendekat kepada Tiongkok ini tentu saja menjadi kekhawatiran dan ancaman bagi ekonomi India. Bhutan adalah pasar yang potensial bagi India. Bhutan juga merupakan tujuan investasi India. India tentu saja tidak rela Bhutan beralih kepada Tiongkok dalam melakukan kerja sama ekonominya.

\section{KESIMPULAN}

Sengketa wilayah perbatasan di dataran tinggi Doklam antara Tiongkok dan Bhutan yang melibatkan India ini menarik. Pembangunan jalan raya yang dilakukan oleh Tiongkok di daerah perbatasannya dengan Bhutan memicu ketegangan bukan hanya dengan Bhutan, tetapi juga dengan India. India yang memiliki perjanjian dengan Bhutan untuk menjamin keamanannya itu langsung menurunkan militernya untuk menghadang proyek pembangunan. Klaim yang tumpang tindih dan interpretasi atas dokumen sejarah yang berbeda membawa masalah ini berlarut bahkan hingga kini. Bahkan hingga disepakatinya expeditious disengagement dan mundurnya kedua pasukan dari perbatasan, penyelesaian kepemilikan wilayah itu masih terkatung-katung.

Lalu, dibalik kesediaan India terlibat langsung dalam masalah ini ternyata tidak hanya karena perjanjian persahabatan yang ditandatanganinya dengan Bhutan. Jalan raya yang dibangun Tiongkok di Doka La ternyata adalah wilayah titik temu perbatasan antara ketiga Negara, Tiongkok-India-Bhutan. Doka La yang sangat dekat dengan Silliguri corridor atau juga disebut Chicken's neck. Daerah ini merupakan wilayah yang sensitive dan penting bagi India sehingga India menganggap bahwa aktivitas Tiongkok di Doklam adalah ancaman bagi kedaulatan wilayahnya.

Selain ancaman bagi pertahanan dan kemanan wilayah, India juga melihat bahwa aktivitas tersebut dapat menjadi ancaman bagi perekonomiannya. Pasalnya, jalan raya yang sedang dibangun Tiongkok di Yadong itu berjarak dekat dengan Thimpu, Bhutan. Jika akses 
kedua wilayah itu baik, kemungkinan aktifitas ekonomi yang terjadi antara kedua wilayah ekonomi tersebut sangat besar. Hal ini menimbulkan kekhawatiran bagi India jika Bhutan pada akhirnya mendekat kepada Tiongkok dan melakukan kerjasama ekonomi dengan Tiongkok. Bhutan adalah sahabat setia India sekaligus mitra dagang dan pasar yang potensial bagi India. Bhutan juga merupakan tujuan investasi India.

\section{DAFTAR PUSTAKA}

Bakry, U. S. (2016). Metode Penelitian Hubungan Internasional. Yogyakarta: Pustaka Pelajar.

Bakry, U. S. (2017). Dasar-Dasar Hubungan Internasional. Depok: Kencana.

Bala, M. (2017). Doklam Dispute: Sino-Indian Perspectives. Ascent International Journal for Research Analysis, 2(3), 28.

Chang, Felix K. (2017). "Conflict Escalation: China and India's Territorial Dispute in the Himalayas," Foreign Policy Research Institute, Retrieved September 20, 2020, from https://www.fpri.org/2017/11/conflict-escalation-china-indias-territorial-disputehimalayas/

Convention of March 17th 1890 between Great Britain and China relating to Sikkim and Tibet.

http://www.claudearpi.net/wpcontent/uploads/2016/11/1890ConventionbetweenGreatBritainandChina-1.pdf

Deepak, B. R. (2017). The Doklam Standoff: What Could Be Done? SADF Comment, Issue No 98, August 5.

Indian-Bhutan Friendship Treaty, 2007. Retrieved September 20, 2020, from https://mea.gov.in/Images/pdf/india-bhutan-treaty-07.pdf

Kumar, M. (1963). Sino-Indian Relations 1950-59. International Studies, 5(1-2), 20-32. https://doi.org/10.1177/002088176300500102

Maitra, R. (2018). The Doklam Stand-Off: A Manifestation of Things Going Wrong?. Asian Journal On Terrorism and Internal Conflict, 21(78), 7-26.

Mas'oed, Mochtar. (1990). Ilmu Hubungan Internasional: Disiplin dan Metodologi, Jakarta, LP3ES, hal 163.

Menon, Prakash \& Kanisetti, Anirudh. (2020). The Doklam Imbroglio, Takshashila Discussion Document, 2018-03, V1.1, Updated July 2020

Ministry of Foreign Affairs of Bhutan. Press Release. https://www.mfa.gov.bt/?p=4799

Nuechterlein, D. E. (1979). National Interest: A new Approach, Orbis. 23(1) (Spring), 57.

Pranoto, Bayu Kurniahadi. (2018). "Analisis Penyelesaian Sengketa Perbatasan TiongkokIndia di Wilayah Himalaya Pasca Perjanjian 2005 Hingga Docklam Standoff 2017"

Raju, K. D. (2020). Doklam and Beyond: Revisiting the India-China Territorial Disputes: An International Law Perspective. India Review, 19(1), 85-105.

Ranjan, A. (2018). India-Bhutan Hydropower Projects: Cooperation and Concerns. ISAS Working Paper, (Vol. 309).

Ratha, K. C. (2020). Deciphering the Doklam Standoff: The Context of the Contest. Jadavpur Journal of International Relations, 24(2), 1-20.

Rejeki, W. S., \& Utomo, T. C. (2019). Pengaruh Kepentingan Nasional dan Interdependensi Ekonomi Terhadap Kebijakan Expeditious Disengagement Tiongkok-India pada Krisis Doklam 2017. Journal of International Relations, 5(4), 727-733. 
Sutriyuwono. (2019). "Strategi diam (Silence Strategy) India dalam Merespons Sengketa Perbatasan antara China dengan Bhutan di Dataran Tinggi Doklam"

Wischer, G. (2019). China Eyes Cracks in a Strategic Indian Partnership. https://intpolicydigest.org/2019/03/16/china-eyes-cracks-in-a-strategic-indianpartnership/ 